\title{
Prospecção tecnológica da importância econômica e industrial do coco e da chia no
}

\section{Brasil}

\author{
Technological prospecting of the economic and industrial importance of coco and chia in Brazil \\ Prospección tecnológica de la importancia económica e industrial del coco y la chía en Brasil
}

Flávia Luiza Araújo Tavares da Silva ORCID: https://orcid.org/0000-0001-7756-9252 Universidade Federal de Sergipe, Brasil E-mail: flavialuats@hotmail.com

Thiago Silva Conceição Meneses ORCID: https://orcid.org/0000-0001-7082-672X Universidade Federal de Sergipe, Brasil E-mail: thiagosilvadm@ hotmail.com

Flávia Escapini Fanchiotti

ORCID: https://orcid.org/0000-0002-1486-2846

Universidade Federal do Pernambuco, Brasil

E-mail: flavia.fanchiotti@ufpe.br

Fábio Oliveira Uchôa

ORCID: https://orcid.org/0000-0002-8952-2192

Universidade Tiradentes, Brasil

E-mail: fabiouchoa@gmail.com

Andréa Gomes da Silva

ORCID: https://orcid.org/0000-0002-8956-0121 Universidade Estadual do Sudoeste da Bahia, Brasil E-mail: agomes@uesb.edu.br

Angela da Silva Borges

ORCID: https://orcid.org/0000-0003-1278-9638 Universidade Federal de Sergipe, Brasil

E-mail: angelasborges@yahoo.com.br

João Antonio Belmino dos Santos

ORCID: https://orcid.org/0000-0003-4924-7154 Universidade Federal de Sergipe, Brasil E-mail: joaoantonio@ufs.br

Patrícia Beltrão Lessa Constant

ORCID: https://orcid.org/0000-0001-7095-940X Universidade Federal de Sergipe, Brasil E-mail: pblconstant@yahoo.com.br

\begin{abstract}
Resumo
Apesar de apresentar uma queda na produção, o Brasil é um dos maiores produtores de coco do mundo, no entanto as sementes de chia ainda são pouco produzidas. A presente pesquisa buscou investigar o mercado desses alimentos por meio de mapeamento em websites e no INPI. Foram totalizadas 19 indústrias de coco, sendo o Nordeste o seu epicentro, e 12 de chia, lideradas pelo Sudeste. Foram encontrados 18 produtos com coco e 9 com chia. O valor do apresentou-se mais elevado em regiões que sua produção é insignificante. O cultivo recente da chia impossibilitou ainvestigação de mercado até o presente momento. Há 359 depósitos de patentes com o descritor geral "coco", enquanto "chia" apresentou apenas 10. A busca por patentes que relacionasse os dois alimentos não obteve resultados. $\mathrm{O}$ estudo mostra a viabilidade de desenvolvimento de produtos que englobe as matérias-primas analisadas, como também o registro de patentes.
\end{abstract}

Palavras-chave: Coco; Chia; Indústria de alimentos; Mercado de alimentos.

\begin{abstract}
Despite showing a drop in production, Brazil is one of the largest coconut producers in the world, however chia seeds are still little produced. This research sought to investigate the market for these foods through mapping on websites and the INPI. There were a total of 19 coconut industries, with the Northeast as its epicenter, and 12 with chia, led by the Southeast. 18 products with coconut and 9 with chia were found. The value of coconut was higher in regions where its production is insignificant. The recent cultivation of chia has made market investigation impossible to date. There are 359 patent applications with the general descriptor "coconut", while "chia" presented only 10. The search
\end{abstract}


for patents relating the two foods did not yield results. The study shows the feasibility of developing products that include the analyzed raw materials, as well as the registration of patents.

Keywords: Coconut; Chia; Food industry; Food market.

\section{Resumen}

A pesar de mostrar una caída en la producción, Brasil es uno de los mayores productores de coco del mundo, sin embargo, las semillas de chía aún se producen poco. Esta investigación buscó investigar el mercado de estos alimentos a través del mapeo en sitios web y el INPI. Había un total de 19 industrias de coco, con el noreste como epicentro, y 12 con chía, lideradas por el sureste. Se encontraron 18 productos con coco y 9 con chía. El valor del coco fue mayor en las regiones donde su producción es insignificante. El cultivo reciente de chía ha hecho que la investigación de mercado sea imposible hasta la fecha. Existen 359 solicitudes de patente con el descriptor general "coco", mientras que "chía" presentó solo 10. La búsqueda de patentes que relacionen los dos alimentos no arrojó resultados. El estudio muestra la viabilidad de desarrollar productos que incluyan las materias primas analizadas, así como el registro de patentes.

Palabras clave: Coco; Chía; Industria alimentaria; Mercado de alimentos.

\section{Introdução}

O Brasil é um dos maiores produtores mundiais de coco, por ser um país tropical. O Cocos nucifera L. é uma das palmeiras mais úteis no mundo, pois dela podem ser aproveitadas diversas partes da planta. A polpa do coco verde é comestível e seus principais constituintes são lipídios, proteínas e carboidratos. O óleo oriundo do coco é considerável saudável para o consumo humano, pois sua composição é rica em ácidos saturados (Santana, 2012).

A cultura do coco tem uma grande importância econômica e social, através da sua capacidade de gerar empregos consegue aumentar a renda de diversos países. No Brasil, essa cultura se dá a maior parte pela comercialização do coco seco para industrialização. Esse processo industrial tem gerado grandes quantidades de resíduos, onde estão sendo realizadas cada vez mais pesquisas sobre meios para reutilização desses resíduos, que muitas vezes são descartados de forma indevida, produzindo assim, substâncias poluidoras (Oliveira, 2015). Apesar da grande produção, o Brasil não é considerado um país competitivo no mercado internacional, sendo necessário implementar medidas de proteção para elevar o nível competitivo (Mazzuchetti et al., 2020).

Segundo dados da ETENE (2018), o Brasil teve uma grande perda (-21,6\%) na sua área de produção entre os anos de 2010 e 2017, em função das adversidades climáticas. Acarretando na morte de coqueirais na maior região produtora do País, o Nordeste. Nesse mesmo período, o Brasil perdeu sua quarta colocação para o Sri Lanca, devido à queda na produção brasileira de $17,6 \%$, passando assim a ser o quinto maior produtor mundial de coco, com 2,3 milhões de toneladas.

A chia (Salvia hispanica L.) é uma planta herbácea que pertence à família das Lamiaceae, família de ervas aromáticas como menta e manjericão. Na era pré-colombiana as sementes de chia eram consideradas um alimento básico para a população da América Central, assumindo uma importância maior que o milho, feijão e outros cereais. $\mathrm{O}$ interesse pela chia tem crescido devido ao reconhecimento pelos efeitos benéficos a saúde e elevadas taxas de proteínas, antioxidantes e fibras (Ramos, 2013). Sendo o cultivo da chia no Brasil recente, as condições climáticas do país oferecem condições favoráveis para uma produção de qualidade e devido a sua importância nutricional há uma grande viabilidade do aumento de renda para os agricultores (Ribeiro \& de Oliveira, 2020).

Segundo Coates (2012), o fato da chia ser uma excelente fonte de fibra dietética, torna-a um alimento com características benéficas para o metabolismo humano, nomeadamente no que se refere à sua capacidade de redução do risco de doenças do trato gastrointestinal, de doenças cardiovasculares e dos níveis de colesterol no sangue. Assim, as sementes de chia, possuindo uma riqueza nutricional, são estão sendo utilizadas como suplementos na produção de pão, barras energéticas, bolachas e outros alimentos funcionais.

Segundo Oriente et al. (2019), a utilização da farinha de chia como um enriquecedor de produtos alimentícios é considerável viável. De fato, que, estudos experimentais a ciência provou que a farinha de semente de chia é rica em proteína, 
fibras, ômega 3 e outros micronutrientes.

Com o impacto da produção desses alimentos, a justificativa dessa pesquisa é mapear as indústrias produtoras, explanar a relevância da sua importância no setor alimentício. Como também, contribuir para acadêmicos e pesquisadores sobre estudos de desenvolvimentos com essas matérias primas, visualizando a importância dos depósitos das invenções a fim de protegê-las.

\section{Metodologia}

O método de estudo da arte e da técnica é utilizado para fazer um levantamento, mapeamento e análise do que se produz considerando áreas de conhecimento, períodos cronológicos, espaços, formas e condições de produção (Ferreira, 2002; Romanowski \& Ens, 2006). O universo, ou população, é o conjunto de elementos que possuem as características que serão objeto do estudo, e a amostra, ou população amostral, é uma parte do universo escolhido selecionada a partir de um critério de representatividade (Vergara, 2007). O universo da pesquisa é composto pelas matérias primas, coco e chia. O critério de representatividade atribuído para a determinação da amostra foram as indústrias que possui identificação nos sites de busca. Desta forma, a amostra selecionada pode ser classificada como não probabilística, sendo que a seleção foi feita por acessibilidade e tipicidade, onde os elementos pesquisados são considerados representativos da população-alvo (Vergara, 2007).

Foi feito um mapeamento em websites, das industrias produtoras de coco e chia como matéria prima, em seguida, a identificação da variedade de alimentos produzidos com base nos mesmos. Para dados de contribuição nacional de patentes foi feita a busca no site do INPI, utilizando os descritores: "coco" e "chia", em dois setores, geral e alimentos. Para ambos, foi verificado também a utilização dos seus derivados como: polpa, farinha, óleo. Após todo o mapeamento realizado, os dados foram analisados e organizados em gráficos e tabelas, sendo interpretados com embasamento no referencial teórico relacionado.

\section{Resultados e Discussão}

\section{Mapeamento das Indústrias}

Através do mapeamento foram encontradas 19 indústrias produtoras de coco distribuídas pelo Brasil (Quadro 1).

Quadro 1: Distribuição das Indústrias produtoras de coco por Estado.

\begin{tabular}{|c|c|}
\hline Indústria & Estado \\
\hline Dikoko & Ceará \\
\hline Ducoco & Ceará \\
\hline Coco do Vale & Paraíba \\
\hline Cocolância & Mato Grosso \\
\hline Coco \& Cia & Rio Grande do Norte \\
\hline Incoco Premium & Alagoas \\
\hline Industria de Alimentos Cooperativa de Pindorama & Alagoas \\
\hline Sococo & Pará; Alagoas; São Paulo \\
\hline Purococo & Rio Grande do Norte \\
\hline Cocoeste & São Paulo \\
\hline Brascoco & Bahia \\
\hline Copra Alimentos & Alagoas \\
\hline Frescoco & São Paulo \\
\hline Aqua Coco & Rio Grande do Norte \\
\hline Dinococo & Paraíba \\
\hline Finococo & Bahia \\
\hline Indiano & Rio Grande do Norte \\
\hline Vita Coco & São Paulo \\
\hline Aja Coco & Pernambuco \\
\hline
\end{tabular}

Fonte: Elaboração própria através de dados obtidos em websites (2020). 
A distribuição dessas indústrias é vista na Figura 1. Onde nota-se que a região Nordeste se encontra como maior cenário industrial com $74 \%$, seguida da região Sudeste e Norte com $21 \%$ e $5 \%$, respectivamente. Não foram encontradas indústrias produtoras do coco nas demais regiões do Brasil registradas em websites.

Figura 1: Porcentagem das indústrias produtoras de coco por região.

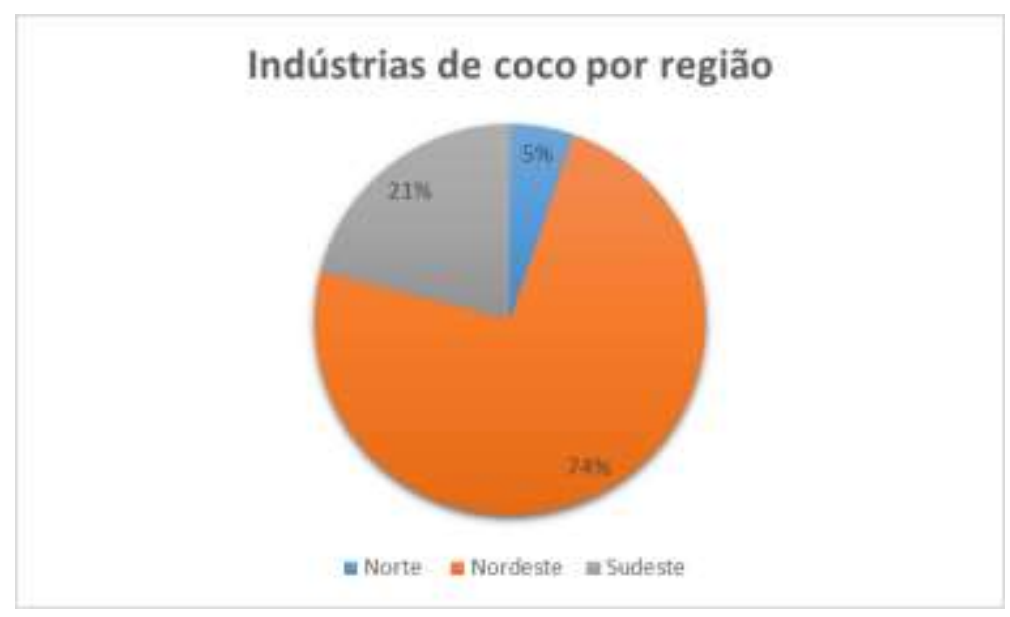

Fonte: Elaboração própria a partir de dados de websites (2020).

A justificativa da maior localização das indústrias se encontrar na região Nordeste é explicada através da sua geografia local. O coqueiro é cultivado em regiões litorâneas, de clima tropical e obtêm perfeitas qualidades com o aumento da temperatura de $27^{\circ} \mathrm{C}$, em situações com temperatura oscilando de $15^{\circ} \mathrm{C}$ não obtêm todo seu potencial produtivo. Essa produção no Nordeste gera lucros sociais e ambientais, harmonizando dados econômicos (Santos, 2018).

Através do mapeamento das indústrias produtoras de chia, foram encontradas 12 unidades distribuídas no país (Quadro 2).

Quadro 2: Distribuição das Indústrias produtoras de chia por Estado.

\begin{tabular}{|c|c|}
\hline Indústria & Estado \\
\hline Produza Foods & Paraná \\
\hline Vitalin & Santa Catarina \\
\hline Kodilar & São Paulo \\
\hline Vitao & Paraná \\
\hline Pazze & Rio Grande do Sul \\
\hline Meissen & São Paulo \\
\hline Veris & São Paulo \\
\hline Nativa & Goiás \\
\hline Leve Crock & Paraná \\
\hline Kinino & São Paulo \\
\hline Natubom & Mato Grosso do Sul \\
\hline Siamar & São Paulo, Minas Gerais, Goiás \\
\hline
\end{tabular}

Fonte: Elaboração própria através de dados obtidos em websites (2020).

Através da Figura 2, nota-se que há uma predominância da produção industrial do país nas regiões Sudeste, Centro Oeste e Sul, com respectivamente $43 \%$, 36\% e $21 \%$. Não foram identificadas indústrias produtoras de chia nas regiões Norte e Nordeste registradas em websites. Segundo Ribeiro e Oliveira (2020), apesar do cultivo da chia no Brasil ser ainda recente, estados como Rio Grande do Sul tiveram bons resultados com a produção. Mesmo as demais regiões do país não possuindo produção significativa, as condições de temperatura, altitude e precipitação apresentadas pelo Brasil são favoráveis as condições exigidas para o cultivo da chia. 
Figura 2: Porcentagem das indústrias produtoras de chia por região.

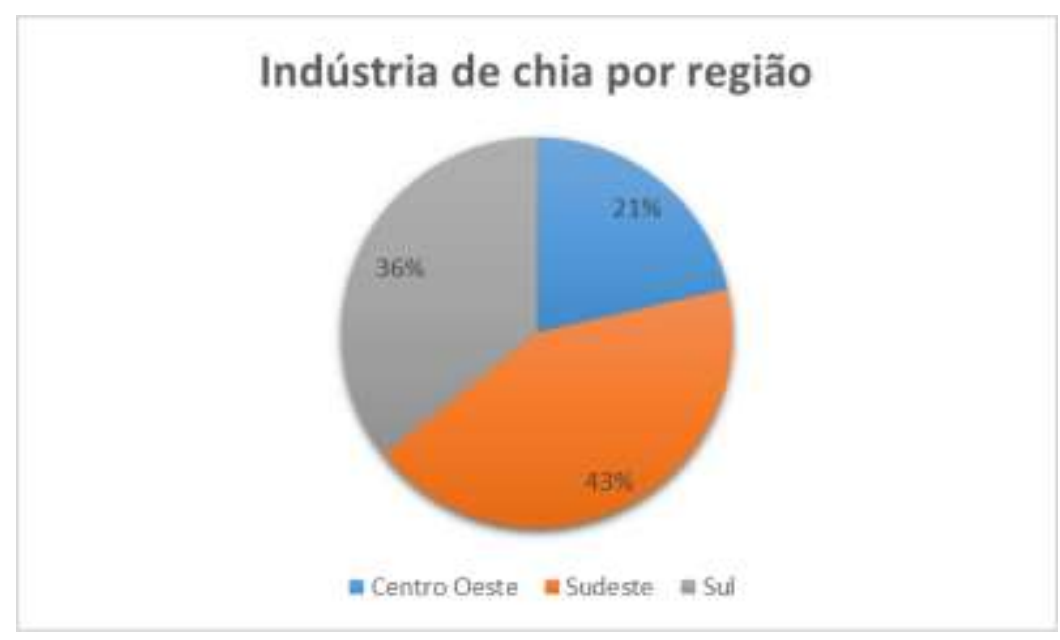

Fonte: Elaboração própria através de dados obtidos em websites (2020).

\section{Produtos à base das matérias primas coco e chia}

Através do mapeamento das indústrias produtoras de coco foi possível identificar todos os produtos comercializados à base de coco pelas mesmas (Figura 3).

Figura 3: Produção das indústrias de coco.

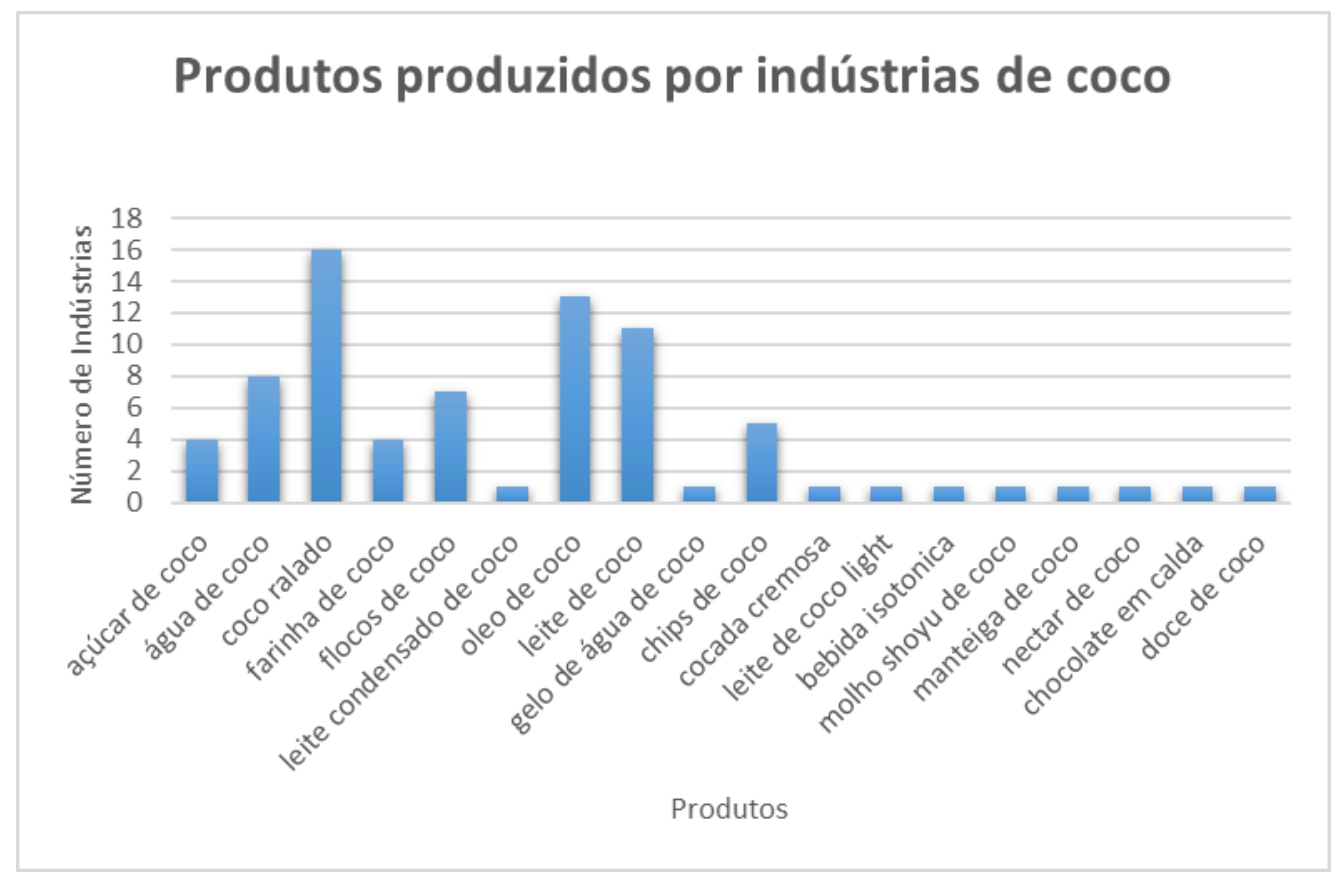

Fonte: Elaboração própria através de dados obtidos em websites (2020).

Dos 18 produtos oriundos do coco encontrados, nota-se que 68,21\% das indústrias comercializam coco ralado, 68,42\% óleo de coco, 57,89\% leite de coco e 42,10\% água de coco. Estes produtos são mais acessíveis economicamente. Os demais produtos são resultados do incentivo a inovação nas indústrias de alimentos, que cada vez mais busca suprir as demandas dos consumidores. A farinha de coco, por exemplo, segundo Copra, (2016) é uma alternativa mais saudável para substituição da farinha branca, devido à grande fonte de fibras alimentares, proteínas, lipídeos, cinzas e carboidratos.

Através do mapeamento da produção industrial de chia no Brasil obteve-se os dados da Figura 4. 
Figura 4: Produção da indústria de chia.

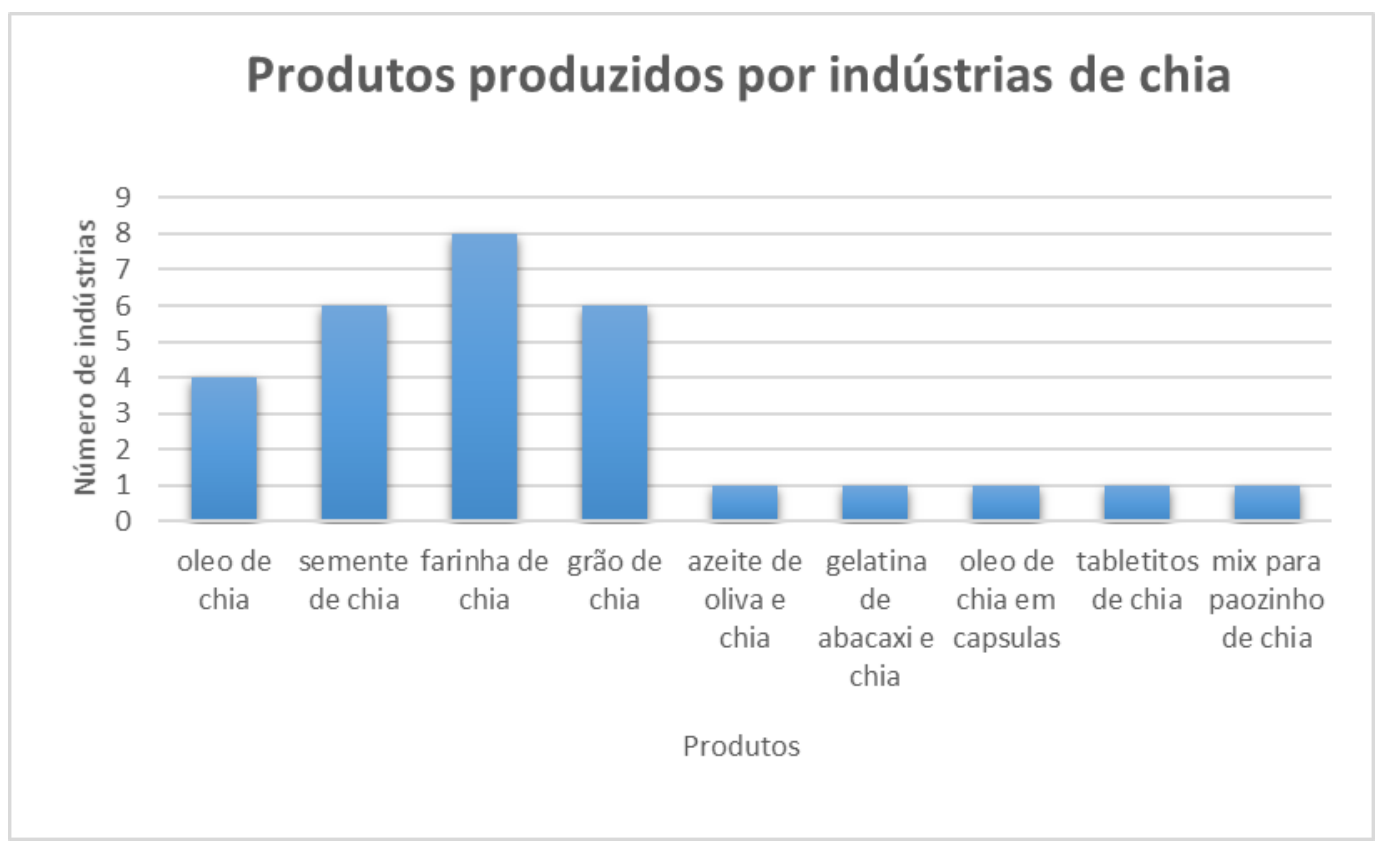

Fonte: Elaboração própria através de dados obtidos em websites (2020).

Foram identificados 9 produtos elaborados através da chia. Nota-se que a maior parte das indústrias possuem uma produção que gira em torno da farinha, sementes, grãos e óleo de chia. Observa-se na Figura 4, que a maior produção é de farinha de chia com 80\%, seguida de sementes e grãos, ambas com 60\% e óleo de chia com 40\%. Os demais produtos identificados como a gelatina com abacaxi e chia, óleo de chia em capsulas, tabletitos de chia e mix para pãozinho de chia são oriundos de inovação e estão entrando recente no mercado. Estes produtos inovadores auxiliam a indústria a ter novas fontes de produtos para as diversas demandas dos consumidores.

\section{Análise de mercado do coco}

O preço do coco encontrado sendo vendido em Ceasa's de vários estados do Brasil apresentou uma enorme variedade. Estes resultados são referentes aos 30 preços mais comuns vendidos em atacado registrados até 23 de novembro de 2020 . O estado do Rio Grande do Sul mostra-se como o estado com o preço mais elevado de $\mathrm{R} \$ 3,18$, os demais estados da região Sul também possuem valores maiores em relação as demais regiões. Entre os estados com essa característica, encontra-se também Mato Grosso e Mato Grosso do Sul com custo elevado de $\mathrm{R} \$ 2,84$ e $\mathrm{R} \$ 2$, 50, respectivamente (Figura 5). Uma das justificativas para esse resultado é devido as regiões não apresentarem produção industrial significativa, por conseguinte o custo leva em consideração a importação. 
Figura 5: Últimos 30 preços mais comum no atacado (Ceasa) de referência dos estados.

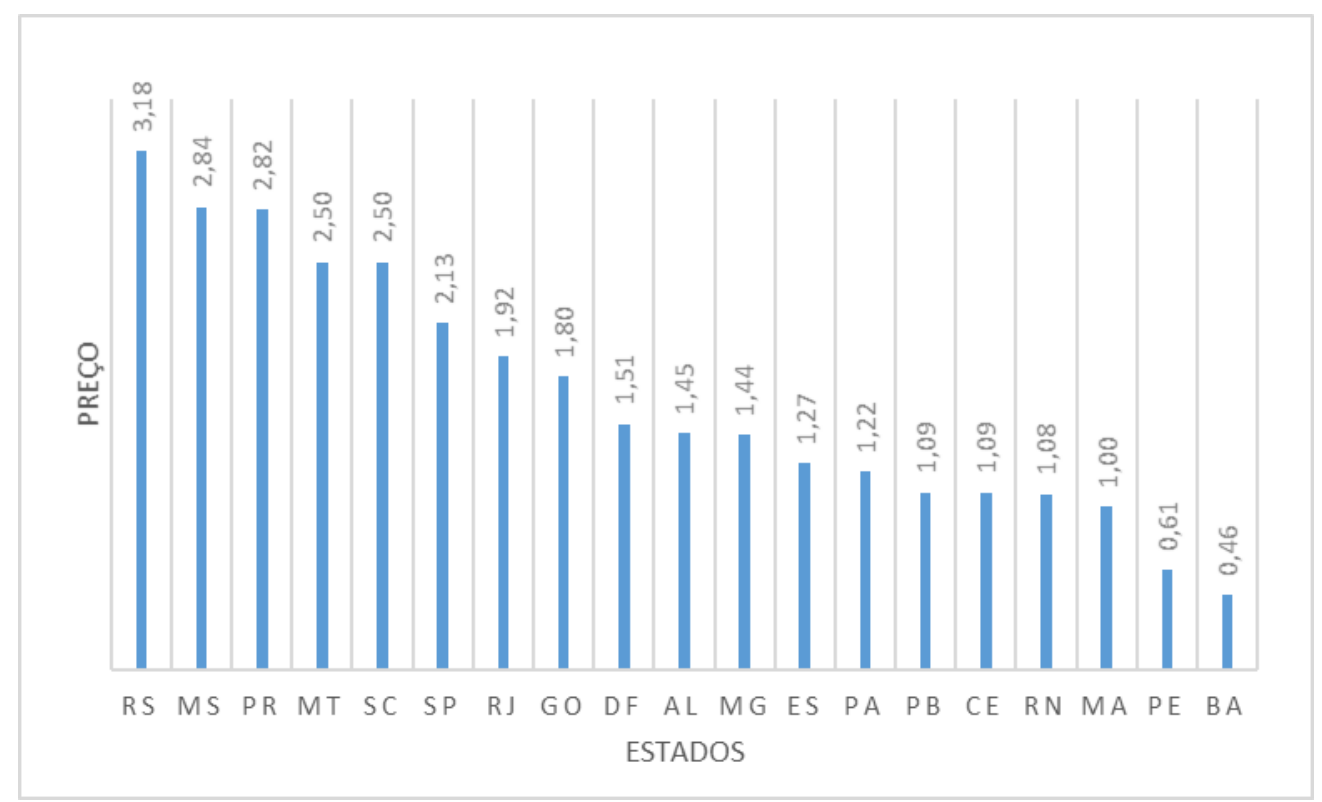

Fonte: Adaptado de CONAB (2020).

A região Nordeste detém dos menores preços encontrados, com destaque para o estado da Bahia que comercializa o coco por $\mathrm{R} \$ 0,46$, o menor preço diante aos demais estados. Isto é caracterizado devido a região Nordeste ser a maior produtora nacional. Alagoas, mesmo fazendo parte da região Nordeste, ainda conta com um preço maior que alguns estados do Norte e Sudeste, como Pará, Minas Gerais e Espirito Santo, respectivamente. Sendo Pará, a segunda maior produtora nacional e com a expansão territorial do cultivo, Minas Gerais e Espirito Santo dispõe de uma grande produção.

Brainer (2018), afirma o Brasil tem participado das exportações, mesmo não estando entre os maiores mercados do mundo. Analisando o Quadro 3, nota-se que apesar do crescimento tanto de exportação quanto de importação do coco no Brasil até 2017, há uma queda considerável em 2018, onde este valor é inferior ao de 2016. Em consequência de o valor de importação ser de aproximadamente 18 vezes mais alto que o de exportação, promove a redução do valor do mercado interno, auxiliando nas disponibilizações do coco para as indústrias e remunerando melhor o produtor, que não necessita da compra de insumos internacionais.

Quadro 3: Brasil no setor de exportação e importação de coco.

\begin{tabular}{|c|c|c|}
\hline \multirow{2}{*}{ Ano } & \multicolumn{2}{|c|}{ Setor } \\
\cline { 2 - 3 } & Exportação (toneladas) & Importação (toneladas) \\
\hline 2016 & 1206 & 19395 \\
\hline 2017 & 1529 & 22135 \\
\hline 2018 & 1078 & 18147 \\
\hline
\end{tabular}

Fonte: AGROSTAT (2018).

Segundo dados obtidos pelo IBGE (2020), houve uma redução na produção de coco no Brasil a partir de 2015, possuindo uma queda maior em 2017. Para 2018 apesar do valor comparado ao ano anterior, em 2019 não conseguiu manter esse crescimento, nos anos anteriores a produção se mostrou estável (Figura 6). 
Figura 6: Quantidade produzida de coco no Brasil

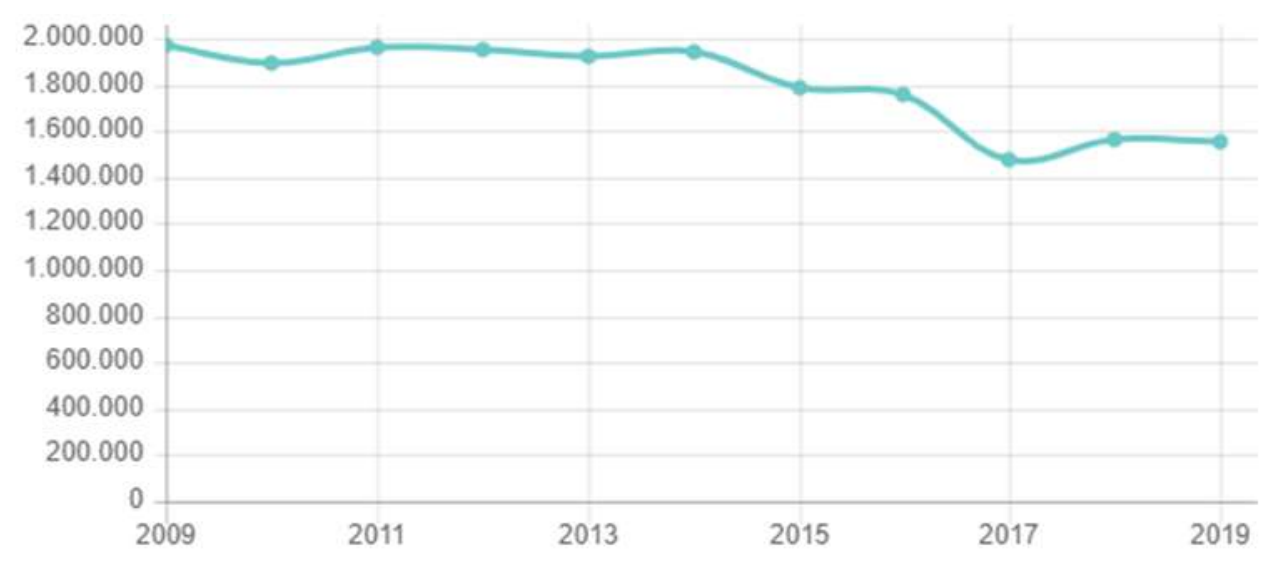

Brasil

Fonte: IBGE (2020).

O valor da produção do coco no Brasil nos últimos 10 anos teve um crescimento significativo até 2014. Após 2015 apesar do instável crescimento, o valor não conseguiu superar o de 2014, visto que em 2019 estes números se aproximam dos valores de 2009 (Figura 7).

Figura 7: Valor da produção do coco no Brasil.

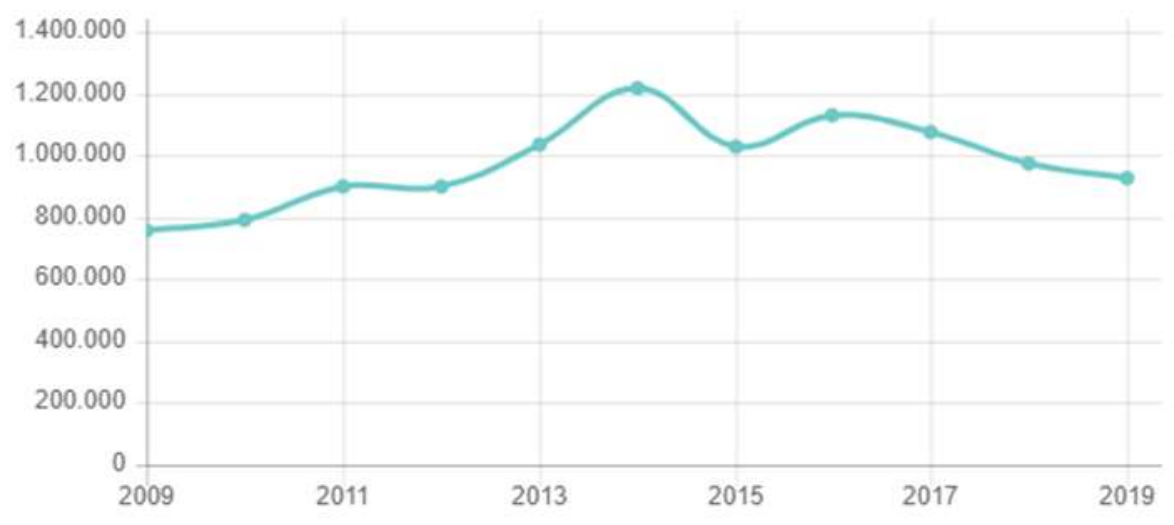

\section{Brasil}

Fonte: IBGE (2020).

Brainer e Ximenes (2020), afirmam que apesar da região Nordeste ser a maior produtora, a mesma detém da menor remuneração por área gerando assim um menor rendimento. Em virtude disso, o produtor não possui uma renda que garanta cobrir todas tecnologias implantas e insumos necessários. É de suma importância que formuladores de políticas públicas atuem de forma que garanta a sustentabilidade socioeconômica da região, para que a mesma consiga manter a sua posição como principal produtora do Brasil.

\section{Análise do mercado da chia}

Migliavacca et al. (2014), afirma que em âmbito nacional o cultivo da chia ainda é muito recente. Os países que se destacam na comercialização são: Austrália, Bolívia, Colômbia, Guatemala, México, Perú e Argentina. Devido ao fato do 
cultivo recente no Brasil, até a presente data há uma dificuldade em encontrar dados referente ao mercado, tanto de importação como exportação. As pesquisas relacionadas a chia abrangem sua composição química e nutricional. Os produtores nacionais encontram dificuldade na comercialização em virtude do mercado comprador não está definido, acarretando a distribuição para principalmente lojas de produtos naturais.

\section{Contribuição Patentária}

Através da busca de dados no site do INPI, foram encontrados os números de patentes depositadas até o presente momento para as matérias primas estudadas: coco (Figura 8) e chia (Figura 9).

Figura 8: Número de patentes encontradas de coco.

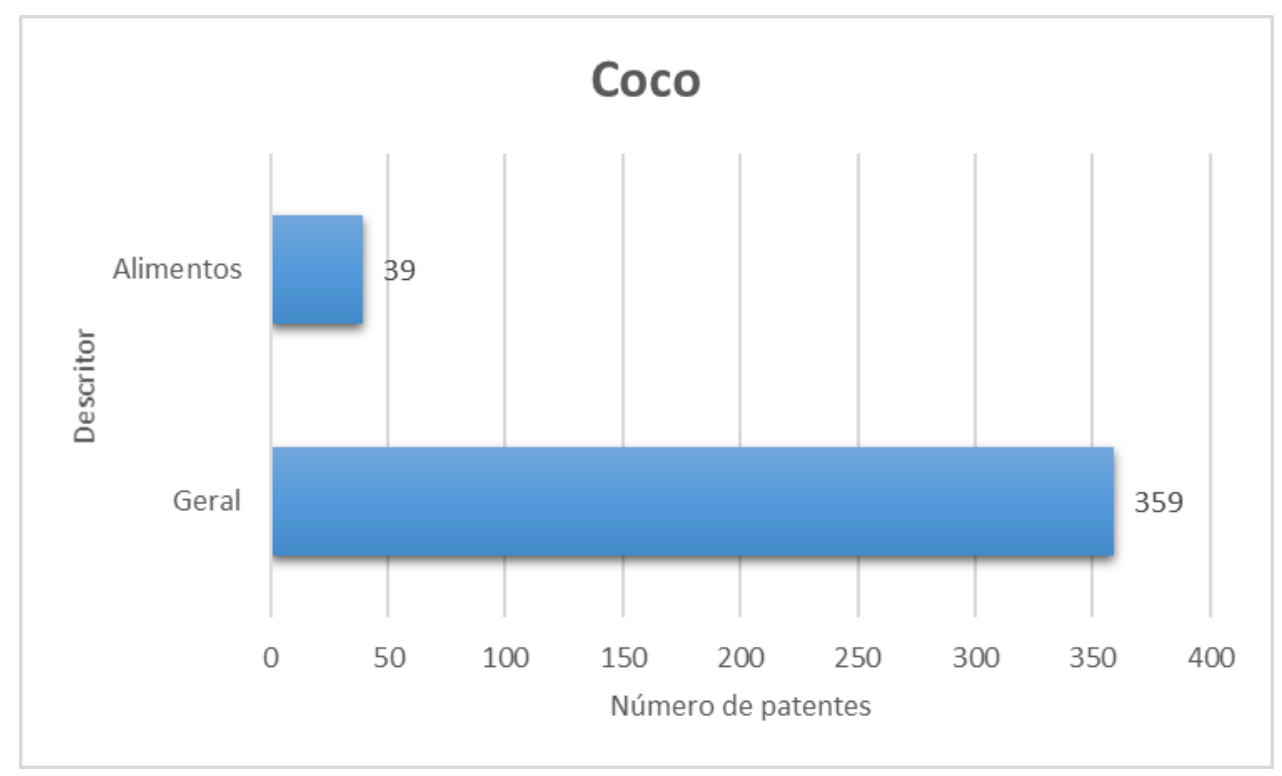

Fonte: Base de dados do INPI (2020).

Para o coco, utilizando o descritor geral foi identificado 359 patentes depositadas, visto que apenas 10,86\% dessas patentes se enquadram no setor de alimentos, com 39 depósitos, um número muito abaixo do esperado. O coco tem sido bastante estudado devido a sua fibra poder ser utilizada de diversas formas, como a patente depositada BR 1020130200506 A2 de 07/08/2013, que dispõe de um processo de preparação de um compósito de fibra de coco-cimento com fins construtivos.

Dos 39 processos encontrados do setor de alimentos para o coco, 2 se enquadraram na proposta desse estudo, sendo as patentes de número BR 1020140181709 A2 de 23/07/2014 e BR 1020150268165 A2 de 22/10/2015. A primeira patente dispõe de uma água de coco em pó utilizada como repositor hidroeletrolítico para atletas, onde a sua composição leva 93\% de água de coco devido a todas as suas propriedades nutricionais e funcionais. A segunda patente dispõe de um snack natural de coco desidratado ou assado e adicionado de tempero, como uma opção lanche saudável e inovador.

Para a chia, o número de patentes encontradas utilizando o descritor geral foi de 10, sendo todas identificadas do setor de alimentos (Figura 8). Esse número ainda é muito baixo em relação ao potencial apresentado pela chia em diversos trabalhos realizados. 
Figura 9: Número de patentes encontradas da chia.

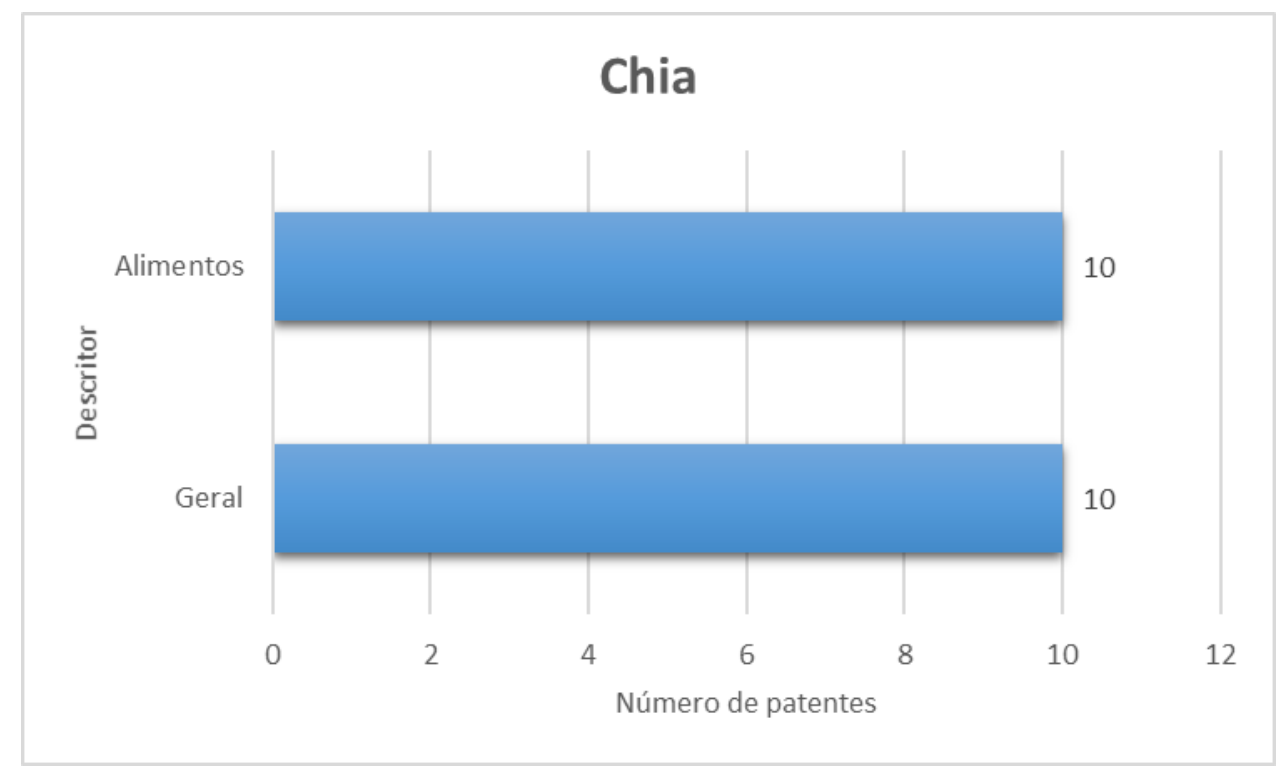

Fonte: Base de dados do INPI (2020).

Dada a composição nutricional da chia, tem sido realizado vários estudos de implementação da mesma na formulação de alimentos enriquecidos, como por exemplo as patentes encontradas no site do INPI - Instituto Nacional de Propriedade Intelectual. A de número BR 1020120212820 A2 de 24/08/2012, que dispõe de uma composição para uma bebida energética a base da semente de chia, de modo que as matérias primas utilizadas conferem uma bebida que traz benefícios à saúde dada a sua característica antioxidante. A patente de número BR 1020170238474 A2 de 06/11/2017, relata um biscoito do tipo cookies que na sua composição há uma substituição parcial da gordura vegetal hidrogenada pelo óleo de chia microencapsulado, apresentando um produto com alto teor de ácidos graxos poli-insaturados.

Através da busca por alimentos à base de coco e chia em conjunto, não foram encontrados até o presente momento nenhum pedido de patente relacionado. Segundo Silva et al. (2020), que realizou o estudo do Potencial da pasta de coco enriquecida com chia, pôde concluir que a mesma adquiriu características espesssante, gelificante e estabilizante, devido a interação da chia, bem como valores de lipídeos de 30,81\% e cinzas de 1,05\%. Apresentando um grande potencial de produção, tanto em matérias primas de baixo custo, como o processo de fabricação da pasta e nos resultados obtidos.

\section{Conclusão}

Através do mapeamento das indústrias, observa-se que $74 \%$ das produtoras de coco encontram-se no Nordeste, as produtoras de chia, sua maior parte $43 \%$, na região Sudeste. Para a maior produção de produtos relacionados ao coco, o coco ralado esteve em $68,21 \%$ das indústrias. Para a chia, $80 \%$ das indústrias produzem a farinha de chia. A avaliação de mercado do coco compreende como a região Nordeste sendo a maior produtora nacional e apresentando o menor preço, encontrando na Bahia, de R \$ 0,46, em contrapartida o Rio Grande do Sul apresentou o maior preço, de $\mathrm{R} \$ 3,18$. Os dados de avaliação de mercado da chia mostraram-se insuficientes. Quando analisado os números de depósitos de patentes em relação às matérias primas, o coco possui um número maior de depósito em relação aos demais.

A produção e utilização desses ingredientes na indústria de alimentos tem uma justificativa concreta, baseada em fatores industriais e de saúde. Contudo, quando analisados em conjunto, o número de patentes é nulo, e, no mercado, suas aplicações são mínimas, mesmo apresentando baixo custo e alta disponibilidade. Com a obtenção destes dados, mostra-se vantajoso o estudo de desenvolvimento de produtos e apropriação tecnológica. Para isto, novas pesquisas precisam ser feitas a 
fim de ampliar o conhecimento da junção das matérias primas estudadas no presente artigo.

\section{Agradecimentos}

Departamento de Tecnologia de Alimentos - Universidade Federal de Sergipe

\section{Referências}

AGROSTAT. (2020) - Estatísticas de comércio exterior do agronegócio brasileiro. Exportação e importação. http://indicadores.agricultura.gov.br/agrostat/index.htm.

Brainer, M. S. C. P. (2018). Produção de coco: o Nordeste é destaque nacional. Caderno Setorial ETENE. Banco do Nordeste do Brasil, 3(61), (Caderno Setorial, n.61).

Brainer, M. S. C. P., \& Ximenes, L. F. (2020) Produção de coco: soerguimento das áreas tradicionais do Nordeste. Banco do Nordeste do Brasil, 5(127), (Caderno Setorial, n. 127).

Coates, W. (2012). Chia: the complete Guide to the ultimate superfood. Sterling Publishing Eds.

Conab (2020) - Companhia nacional de abastecimento. Prohort - Programa brasileiro de Modernização do Mercado de Hortigranjeiro. Média mensal dos preços. https://www.conab.gov.br/info-agro/hortigranjeiros-prohort.

Copra (2016). Farinha de coco. Maceió. <http://www.copraalimentos.com.br/produto/80/farinha-de-coco>.

ETENE. (2018). Escritório técnico de estudos econômicos do nordeste. Banco do Nordeste.

Ferreira, N. S. de A. (2002). As pesquisas denominadas “estado da arte”. Educação \& Sociedade, 23(79), $257-272$.

IBGE. (2020). Produção Agrícola - Lavoura Permanente. https://cidades.ibge.gov.br/brasil/pesquisa/15/0?indicador=11930\&tipo=grafico

Mazzuchetti, R. N., Neto, S. C., Cunha, E. D., \& de Oliveira, N. S. (2020). A análise pest dos resíduos do Coco Verde no Brasil. Brazilian Journal of Development, 6(7), 46098-46111

Migliavacca, R. A. et al. (2014). O cultivo da chia no brasil: futuro e perpectivas. Journal Of Agronomic Sciences. Umuarama, p. 161-179. http://www.dca.uem.br/V3NE/13.pdf.

Oliveira, M. B. dos S. (2015). Avaliação da capacidade antioxidante e perfil químico de extratos etanólicos da fibra da casca de coco (Cocos Nucifera L. (PALMAE)). 99 f. Dissertação (Mestrado) - Curso de Química e Biotecnologia, Universidade Federal de Alagoas, Maceió, 2015.

Oriente, S. F. do et al. (2019). Elaboração e caracterização físico-química de iogurtes de ameixa adicionados da farinha de chia. Magistra30(1), 78-95.

Ramos, S. C. F. (2013). Avaliação das propriedades gelificantes da farinha de chia (Salvia hispanica L.): Desenvolvimento de novas aplicações culinárias. 2013. 111 f. Dissertação (Mestrado) - Curso de Ciências Gastronómicas, Universidade de Lisboa, Lisboa.

Ribeiro, I. Y. L., \& de Oliveira, C. M. (2020). Viabilidade da produção de chia no brasil. Encontro Internacional de Gestão, Desenvolvimento e Inovação (EIGEDIN), 4(1)

Romanowski, J. P., Ens, R. T. (2006). As pesquisas denominadas do tipo “estado da arte” em educação. Diálogo Educ., 6(19), 37-50.

Santana, I. A. (2012). Avaliação quimica e funcional de polpa de coco verde e aplicação em gelato comestível. 2012.107 f. Dissertação (Mestrado) - Curso de Engenharia de Processos Quimicos e Bioquimicos, Escola de Engenharia de Mauá, São Caetano do Sul, 2012.

Silva, F. L. A. T. da et al. (2020). Potencial da pasta de coco enriquecida com chia. In: Congresso brasileiro de saúde e alimentação, 7., 2020, Aracaju. Anais [...] Cbsa. p. 28-28. https://s3-sa-east-1.amazonaws.com/congresse-me-assets-host/articles/archives/3441/original/POTENCIAL_DA_PASTA_DE_COC O_ENRIQUECIDA_COM_CHIA.pdf?1602074194.

Vergara, S. C. (2007). Projetos e relatórios de pesquisa em administração. (9a ed.), Atlas. 